\title{
The impact of human resource practices on psychological empowerment
}

\author{
Fatemeh Moradi* and Naser Sanai Dashti
}

Department of Management and Accounting, Central Branch, Islamic Azad University, Tehran, Iran

\begin{tabular}{l}
\hline C H R O N I C L E \\
\hline Article history: \\
Received January 5, 2016 \\
Received in revised format April \\
15,2016 \\
Accepted June 7, 2016 \\
Available online \\
June 8, 2016 \\
\hline Keywords: \\
Psychological empowerment \\
Human resource practices \\
National Iranian oil company \\
\end{tabular}

\section{A B S T R A C T}

\begin{abstract}
The main objective of this study is to explain the relationship between human resource management (HRM) and psychological empowerment among the employees who worked for the National Iranian oil company (NIOC). The study population includes all NIOC's 950 employees, where 276 people were randomly chosen as sample study. The survey uses a questionnaire originally developed by Spreitzer (1995) [Spreitzer, G. M. (1995). Psychological empowerment in the workplace: Dimensions, measurement, and validation. Academy of management Journal, 38(5), 1442-1465.] to measure psychological empowerment and designs another questionnaire for measuring HRM. Cronbach alphas for psychological empowerment and HRM are 0.856 and 0.839 , respectively. The results have indicated that there was a positive and meaningful relationship between psychological empowerment and HRM.
\end{abstract}

\section{Introduction}

Human resource management (HRM) (Wright \& McMahan, 1992) plays essential role on the success of any organization and there are several studies on measuring the effects of HRM on the performance of firms (Barton \& Barton, 2011; Bowen \& Lawler III, 2006). Ahmad and Schroeder (2003) attempted to generalize the efficacy of different HRM practices in the context of country and industry, concentrating on the impacts of these practices on operations. Chow et al. (1999) studied cultural influences on informal information sharing in Chinese and Anglo-American organizations based on some exploratory study. They suggested the importance of individual differences, individual assertiveness, and corporate culture in affecting informal information sharing in Australia. Collins and Clark (2003) explored the relationship between human resources (HR) practices and firm performance by examining the relationships between a set of network-building HR practices, aspects of the external and internal social networks of top management teams, and firm performance. They reported that the relationships between the HR practices and firm performance were mediated through their top managers' social networks.

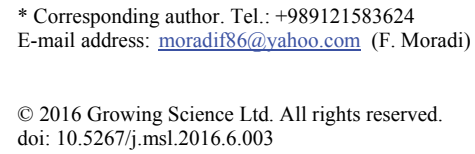


According to Dessler (2006), several Chinese candidates may be unwilling to offer themselves during an interview because of a strong cultural bias against boasting. Western organizations' attempt on employee empowerment could be alien to those raised in the more conventional Chinese culture. Lee et al. (2010) performed an investigation on the relationship between HRM practices, business strategy and firm performance in steel industry in Taiwan. They reported that HRM practices could be positively associated with firm performance, there was a close relationship between HRM practices and business strategy, business strategies could be positively associated with firm performance and integrating HRM practices with business strategies could be positively associated with firm performance.

Psychological capital is associated with one's positive psychological resources, which includes selfefficacy, hope, optimism, and resilience, and psychological capital which are important resources for organizational behavior and effectiveness. You (2016) examined the effect of psychological capital on students' learning in an academic context, and proposed some structural models to test the relationship among students' psychological capital, learning empowerment, and engagement. They reported that college students' psychological capital maintained a positive relationship with learning empowerment, and learning empowerment fully mediated the relationship between psychological capital and engagement. Quiñones et al. (2013) investigated whether psychological empowerment could act as a personal resource mediating the motivational process from job resources to work engagement. They reported that job resources could increase the perception of being empowered at work, which then represents an essential factor to enhance work engagement.

Lee and Nie (2014) investigated the predictive relationships among teachers' perceptions of principal's and immediate supervisor's empowering behaviours, teachers' psychological empowerment and three teachers' work-related outcomes in terms of job satisfaction, organisational commitment and professional commitment. They reported that the four dimensions of psychological empowerment (i.e. 'meaning', 'competence', 'autonomy', and 'impact') mediated the relationships between teachers' perceptions of immediate supervisor's empowering behaviours and teachers' work-related outcomes. Bitmiş and Ergeneli (2011) examined the mediating effect of leader member exchange on the relationship between psychological empowerment and job satisfaction in 21 st century workplace.

\section{The proposed study}

The main objective of this study is to explain the relationship between human resources management (HRM) and psychological empowerment of employees in the National Iranian oil company (NIOC). The study population includes all NIOC's 950 employees and the sample size is calculated as follows,

$$
n=\frac{N \times z_{\alpha / 2}^{2} \times p \times q}{\varepsilon^{2} \times(N-1)+z_{\alpha / 2}^{2} \times p \times q},
$$

where $N$ is the population size, $p=1-q$ represents the yes/no categories, $z_{\alpha / 2}$ is CDF of normal distribution and finally $\varepsilon$ is the error term. Since we have $p=0.5, z_{\alpha / 2}=1.96$ and $N=950$, the number of sample size is calculated as $n=276$. Therefore, 276 people are randomly chosen as sample study. The survey uses a questionnaire originally developed by Spreitzer (1995) to measure psychological empowerment and designs another questionnaire for measuring HRM. There are five hypotheses as follows,

1. There is a relationship between team work activities and psychological empowerment in NIOC.

2. There is a relationship between extensive training programs and psychological empowerment in NIOC.

3. There is a relationship between information sharing and psychological empowerment in NIOC. 
4. There is a relationship between performance-based pay and psychological empowerment in NIOC.

5. There is a relationship between performance feedback and psychological empowerment in NIOC.

We first examine whether the data were normally distributed using Kolmogorov-Smirnov test. Table 1 shows the results of our survey. As we can observe from the results of Table 1, all variables are normally distributed when the level of significance is five percent.

Table 1

The results of Kolmogorov-Smirnov test

\begin{tabular}{lccc}
\hline Variable & Kolmogorov-Smirnov Z & Sig. & Result \\
\hline Team work activities & 1.112 & 0.225 & Normal \\
Information sharing & 1.149 & 0.109 & Normal \\
Performance-based pay & 1.130 & 0.215 & Normal \\
Extensive training programs & 1.198 & 0.092 & Normal \\
Performance feedback & 1.224 & 0.089 & Normal \\
HRM activities & 1.123 & 0.218 & Normal \\
Psychological empowerment & 1.169 & 0.098 & Normal \\
\hline
\end{tabular}

\section{The results}

In this section, we present the results of the implementation of different parametric tests such as Pearson correlation, stepwise regression and one-way t-test to examine the hypotheses of the survey. Table 2 shows the results of Pearson correlation to examine the hypotheses of the survey, and as we can observe, there are some positive and meaningful relationships between HRM components and psychological empowerment.

\section{Table 2}

The summary of Pearson correlation ratios

\begin{tabular}{lccl}
\hline Variable & Correlation ratio & Sig. & Result \\
\hline Team work activities & 0.429 & 0.000 & Confirmed \\
Information sharing & 0.465 & 0.000 & Confirmed \\
Performance-based pay & 0.340 & 0.000 & Confirmed \\
Extensive training programs & 0.385 & 0.000 & Confirmed \\
Performance feedback & 0.411 & 0.089 & Confirmed \\
HRM activities & 0.685 & 0.000 & Confirmed \\
\hline
\end{tabular}

Table 3 shows the results of regression method between psychological empowerment as dependent variable and HRM components as independent variables.

\section{Table 3}

The results of regression model

\begin{tabular}{lcccc}
\hline Variable & $\mathrm{B}$ & Beta & t-value & Sig. \\
\hline Team work activities & 0.255 & 0.261 & 5.376 & 0.000 \\
Information sharing & 0.282 & 0.287 & 6.063 & 0.000 \\
Performance-based pay & 0.135 & 0.126 & 2.562 & 0.012 \\
Extensive training programs & 0.157 & 0.162 & 2.709 & 0.008 \\
Performance feedback & 0.236 & 0.242 & 4.557 & 0.000 \\
\hline
\end{tabular}

Adjusted R-Square $=0.492$ F-value $=66.203(0.000) \mathrm{df}=270,5$ 
According to the results of Table 3, F-value is equal to 66.203 with Sig. $=0.000$, which means there was a linear relationship between independent variables and dependent variable. Adjusted R-Square is equal to 0.492 , which means that independent variables, HRM variables, could approximately describe $49 \%$ of the changes on dependent variable, psychological empowerment. All t-value numbers are statistically significant. We also used one-way t-student test to measure the effects of psychological empowerment and Table 4 shows the summary of our findings and we can confirm that all psychological empowerment components are within desirable levels.

Table 4

The summary of the implementation of t-value on the effects of psychological empowerment

\begin{tabular}{lccccccc}
\hline & & & \multicolumn{5}{c}{ Interval } \\
\hline Variable & t-value & df & Mean & Sig. & lower & upper & Result \\
\hline Competence & 26.437 & 275 & 3.846 & 0.000 & 0.7836 & 0.9097 & desirable \\
Impact & 7.999 & 275 & 3.370 & 0.000 & 0.2795 & 0.4620 & desirable \\
Trust & -9.459 & 275 & 2.477 & 0.000 & -0.6318 & -0.4141 & desirable \\
Autonomy & 6.082 & 275 & 3.252 & 0.000 & 0.1707 & 0.3341 & desirable \\
Being meaningful & 11.323 & 275 & 3.572 & 0.000 & 0.4729 & 0.6720 & desirable \\
Psychological & 9.251 & 275 & 3.303 & 0.000 & 0.2392 & 0.3685 & desirable \\
\hline
\end{tabular}

Finally, we have applied one-Sample t-student test to measure the effects of HRM. Table 4 shows the summary of our findings and we can confirm that most HRM components are not within desirable levels. In other words, HRM activities including Performance-based pay, Extensive training programs and Performance feedback were not within the desirable levels and only Team work activities and Information sharing are somewhat desirable.

\section{Table 5}

The summary of the implementation of t-value on the effects of HRM components Interval

\begin{tabular}{lccccccc}
\hline Variable & t-value & df & Mean & Sig. & lower & upper & Result \\
\hline Team work activities & -1.372 & 275 & 2.924 & 0.171 & -0.1831 & 0.0327 & About average \\
Information sharing & -1.088 & 275 & 2.939 & 0.277 & -0.1696 & 0.0488 & About average \\
Performance-based pay & -8.505 & 275 & 2.569 & 0.000 & -0.5298 & -0.3307 & Undesirable \\
Extensive training programs & -8.151 & 275 & 2.695 & 0.000 & -0.3779 & -0.2308 & Undesirable \\
Performance feedback & -13.224 & 275 & 2.516 & 0.000 & -0.5557 & -0.4117 & Undesirable \\
HRM activities & -7.987 & 275 & 2.729 & 0.000 & -0.3375 & -0.2040 & Undesirable \\
\hline
\end{tabular}

\section{Conclusion}

In this paper, we have presented an empirical investigation to study the effects of HRM activities on psychological empowerment among selected people in an oil company. The study used a well-known questionnaire introduced by Spreitzer (1995) to measure psychological empowerment and designed a questionnaire to measure HRM activities. The implementation of Pearson correlation test as well as stepwise regression technique has indicated meaningful relationship between the mentioned factors. The results of this survey are consistent with other findings such as Lee et al. (2010), Zimmerman (1995), Cheung et al. (2012 and Spreitzer (1996). Allahyari et al. (2011), for instance, investigated the relationship between the empowerment with organizational learning among the employees who work for the University of Tehran. The implementation of the Pearson Correlation indicated that empowerment had positive relationship with organizational learning. Moreover, the implementation of the regression analysis indicated that sense of incorporation with others and sense of competence could predict the organizational learning. Moreover, the result of One Sample T-Test indicated that there was 
no significant difference between empowerment and organizational learning of male and female employers. In other words, gender did not have any impact on the relationship. Finally, they reported that there was not any significant difference between empowerment and organizational learning of managers and employees.

\section{Acknowledgement}

The authors would like to thank anonymous referees for constructive comments on earlier version of this paper.

\section{References}

Ahmad, S., \& Schroeder, R. G. (2003). The impact of human resource management practices on operational performance: recognizing country and industry differences. Journal of operations Management, 21(1), 19-43.

Allahyari, R., Mirkamali, S. M., \& Kharazi, K. (2011). Survey of relationship between the psychological empowerment of employees with organizational learning. Procedia-Social and behavioral Sciences, 30, 1549-1554.

Barton, H., \& Barton, L. C. (2011). Trust and psychological empowerment in the Russian work context. Human Resource Management Review, 21(3), 201-208.

Bitmiş, M. G., \& Ergeneli, A. (2011). Contingency approach to strategic management: a test of the mediating effect of leader member exchange on the relationship between psychological empowerment and job satisfaction in 21st century workplace. Procedia-Social and Behavioral Sciences, 24, 1143-1153.

Bowen, D. E., \& Lawler III, E. E. (2006). The empowerment of service workers: What, why, how, and when. Managing innovation and change, 155-69.

Cheung, C., Baum, T., \& Wong, A. (2012). Relocating empowerment as a management concept for Asia. Journal of Business Research, 65(1), 36-41.

Chow, C. W., Harrison, G. L., McKinnon, J. L., \& Wu, A. (1999). Cultural influences on informal information sharing in Chinese and Anglo-American organizations: an exploratory study. Accounting, Organizations and Society,24(7), 561-582.

Collins, C. J., \& Clark, K. D. (2003). Strategic human resource practices, top management team social networks, and firm performance: The role of human resource practices in creating organizational competitive advantage. Academy of Management Journal, 46(6), 740-751.

Dessler, G. (2006). Expanding into China? What foreign employers should know about human resource management in China today. SAM Advanced Management Journal, 71(4), 11.

Lee, F. H., Lee, T. Z., \& Wu, W. Y. (2010). The relationship between human resource management practices, business strategy and firm performance: evidence from steel industry in Taiwan. The International Journal of Human Resource Management, 21(9), 1351-1372.

Lee, A. N., \& Nie, Y. (2014). Understanding teacher empowerment: Teachers' perceptions of principal's and immediate supervisor's empowering behaviours, psychological empowerment and work-related outcomes.Teaching and Teacher Education, 41, 67-79.

Quiñones, M., Van den Broeck, A., \& De Witte, H. (2013). Do job resources affect work engagement via psychological empowerment? Amediation analysis. Revista de Psicología del Trabajo y de las Organizaciones, 29(3), 127.

Spreitzer, G. M. (1995). Psychological empowerment in the workplace: Dimensions, measurement, and validation. Academy of management Journal, 38(5), 1442-1465.

Spreitzer, G. M. (1996). Social structural characteristics of psychological empowerment. Academy of Management Journal, 39(2), 483-504.

Wright, P. M., \& McMahan, G. C. (1992). Theoretical perspectives for strategic human resource management. Journal of management, 18(2), 295-320. 
You, J. W. (2016). The relationship among college students' psychological capital, learning empowerment, and engagement. Learning and Individual Differences, 49, 17-24.

Zimmerman, M. A. (1995). Psychological empowerment: Issues and illustrations. American Journal of Community Psychology, 23(5), 581-599.

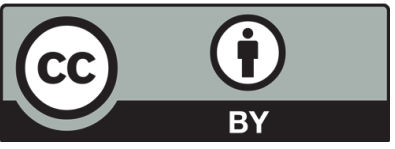

(C) 2016 by the authors; licensee Growing Science, Canada. This is an open access article distributed under the terms and conditions of the Creative Commons Attribution (CC-BY) license (http://creativecommons.org/licenses/by/4.0/). 